\title{
Pheromones in Human Urine: A Study
}

\author{
K. P. Skandhan ${ }^{1,2 *}$, S. Amith ${ }^{3}$, H. Vadodaria ${ }^{2}$, B. N. Mazumdar ${ }^{2}$, K. Dhuri ${ }^{4}$, M. Gondalia ${ }^{2}$ \\ ${ }^{1}$ Department of Physiology, Sree Narayana Institute of Medical Sciences, Ernakulam, India \\ ${ }^{2}$ Department of Physiology, Byramjee Jeejeebhoy Medical College, Ahmedabad, India \\ ${ }^{3}$ Southeast Alabama Medical Center, Dothan, USA \\ ${ }^{4}$ Department of Kayachiktsa, Gujarat Ayurveda University, Jamnagar, India \\ Email: "kpskandhan@gmail.com
}

Received November 13, 2012; revised December 15, 2012; accepted December 27, 2013

Copyright (c) 2013 K. P. Skandhan et al. This is an open access article distributed under the Creative Commons Attribution License, which permits unrestricted use, distribution, and reproduction in any medium, provided the original work is properly cited.

\begin{abstract}
The present study was conducted to understand if pheromone or any similar substance was present in human semen and whether it could be recognized by smell. One hundred and fifty two subjects of either sex participated in this study. The study lasted for one month. They were to identify urine by smell. Daily first urine sample was submitted by five male and five female subjects for this study. Menstrual status of female subjects was recorded. Many distinguished the smell of urine of male from that of female. Interestingly male subjects recognized the smell of female urine of ovulation day. Reason may be pheromone. A woman may be releasing maximally pheromone on this day. This supports the theory of pheromone which attracts a man to a woman on her ovulation day.
\end{abstract}

Keywords: Pheromone; Human; Male Urine; Female Urine

\section{Introduction}

Mammals displayed manifold responses to the odour signal depending upon behavioral situation, the physiological state of an individual and other social and physical environments [1]. It was observed that menstrual cycle influenced grooming behavior and sexual activity in male rhesus monkey [2]. Michael and Keverne [3] observed the smell from vaginal secretion of these animals elicited sexual activity of male partners, which was absent after ovariectomy [2]. Similar examples of pheromonal activities of different mammals in both sexes were established. The existence of pheromones in human is yet proved, though it was well known that sense of smell was a primary sensory modality in the initial stage of heterosexual development. During oedipal period, a child got attracted to the odour of heterosexual parent and repulsed by the odour of the ipsi-sexual parent [4].

There was possibly increased olfactory sensitivity among women in the middle of menstrual cycle to exaltolide (Lactone of 15-hydroxy pentadecanoic acid) [5] and androstenol, (5- $\alpha$ Androst-16-en- $3 \alpha$-oh) two putative human pheromones [6]. Synchronization of menstrual cycle in cohabitating females [7,8] and shortening of menstrual cycle after exposure to men [9] were few evi-

"Corresponding author. dences supporting odour influencing the physiological process of menstrual cycle. Further supporting pheromone theory, Nicholson [10] argued that a semochemical substance escaped from mouth of a person to his/her partner while kissing and which made a lasting bond between them. Grammer et al. [11] and Skandhan et al. [12] reviewed role of pheromones in human in behavioral and reproduction biology.

It is known that smell influences the activities of a person. A pleasant smell is everyone's choice. Room fragrance, body spray and perfume are best example. "Aroma therapy" is becoming popular everywhere.

The observations by researchers suggested that there was an excretion of an odorant exuded by human female which attracted male $[13,14]$. The present study was aimed to find out, if such an odorant was present in liberated through human male and female urine.

\section{Materials and Methods}

Five male and five female medical students (age 18 - 20 years) who were hostelites, had volunteered to submit daily their first urine sample throughout study lasting one month. They were clinically healthy and vegetarian by habit. Restrictions on food from outside hostel (except for tea or coffee) were made. Female volunteers were with regular menstrual cycle and they recorded daily 
their basal body temperature. This was to understand their menstrual status especially the ovulation day.

Everyday each urine sample was given a code number. Coded samples were distributed in small plastic dispensers. They were kept on different tables in a long hall. Along with it, in similar containers kerosene, liquid asafoetida, soap solution and eau-de-cologne were placed with different code numbers. Distilled water with code number was also placed to check the honesty of participants, about reporting smell.

One hundred and fifty two male and female medical students of 18 - 20 years of age participated in the study. They were clinically healthy. If any subject suffered from rhinitis or similar ailment was excluded from the study on ill days. Menstrual history of all female participants was recorded. The study lasting for one month was restricted between 8.30 and $9.00 \mathrm{am}$. Participants were to smell the content in each container and report what type smell it was, which was regularly recorded. When a participant reported urine he or she was to smell again and to report if given was of male or female.

\section{Results}

The smell of kerosene, asafoetida, soap, eau-de-cologne and urine were identified by all subjects. None of them reported any smell from distilled water. Smell of female urine samples was identified by $29.73 \%$ of male and $19.14 \%$ of female subjects. Similarly, $24.73 \%$ of male and $10.26 \%$ of female subjects identified male urine samples correctly.

Considering the female participants menstrual status, Figure 1 was plotted. On the day of ovulation, they were almost not able to identify neither male nor female urine of any day from menstrual cycle except that from progestational phase (Figure 2).

Female subjects response to female urine of different phases and urine from pregnant women was plotted (Figure 2).Statistical analysis did not show any significant result.

\section{Discussion}

Existence of human pheromones has not been established, though evidences were suggestive of it. New born babies recognized mother's nipples by their smell, probably created by the secretion of glands in areola and not either by milk or colostrum [15]. Mothers' recognized their newborn babies by odour [16]. Breastfed infants recognized their mothers' scent [17]. It was understood that newborn child was attracted to smell of heterosexual parent lead- ing to his/her sexual development [4].

Synchronisation of menstruation experienced by women staying in dormitory [7] or in hostel [8] or among lesbians [18] seen was possibly due to pheromone influence [7].

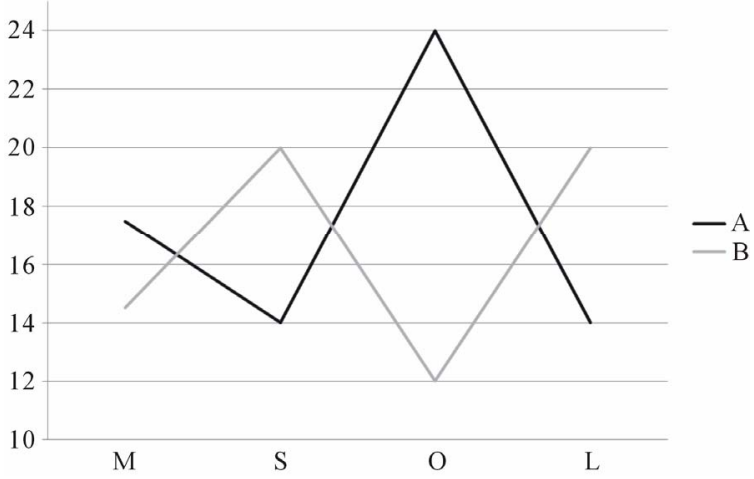

Figure 1. Identification of smell of urine. A: Male response to female urine collected on different days of menstrual cycle. B: Female response to male urine shown on her different days of menstrual cycle. $X$ Axis: $M=$ Menstruating day; $\mathrm{S}=$ Secretory phase; $\mathrm{O}=$ Ovulation phase; $\mathrm{L}=$ Luteal phase; Y Axis: \% of performance.

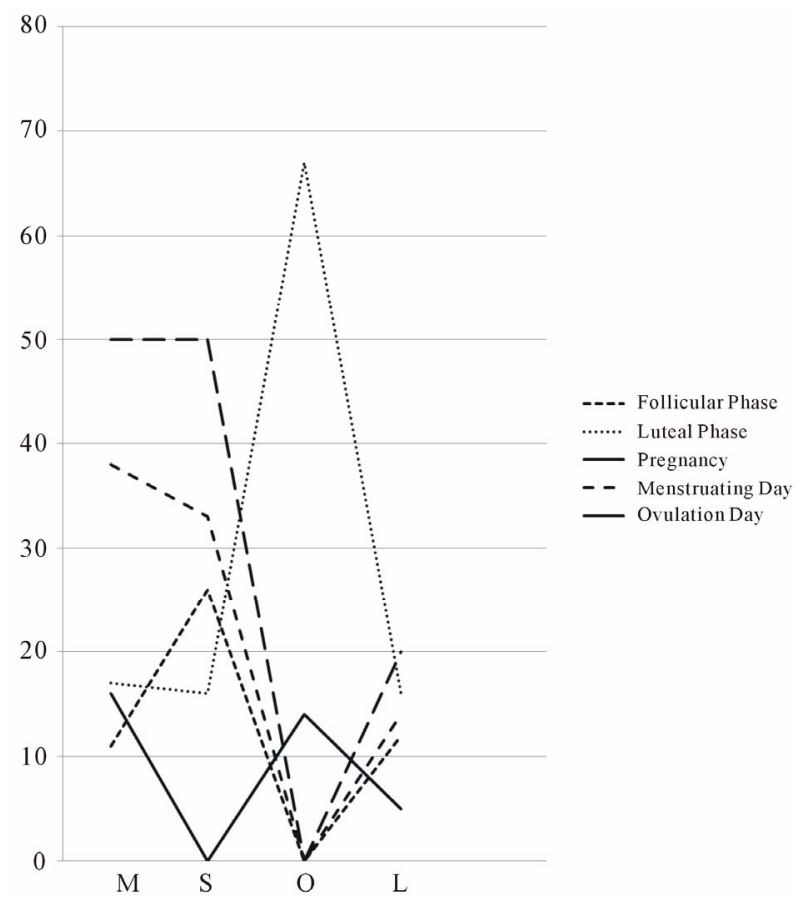

Figure 2. Response to urine of different days of menstrual cycle shown by women on different days of their menstrual cycles. $X$ Axis: $M=$ Menstruating day; $S$ = Secretory phase; $\mathbf{O}=$ Ovulation phase; $\mathbf{L}=$ Luteal phase. $Y$ Axis: \% of performance.

There might be special olfactory sensory receptors for pheromones like vomeronasal receptors in rats. In human such receptors were not identified $[19,20]$. Human civilization made smell not necessary for food procurement or identifying enemies or understanding opposite sex. This might have lead to the loss of appreciation and importance of smell in man.

Animal experiments on various species irrevocably concluded that pheromone was present in its urine. Male 
urine smell made female rat [21] and guinea pig [22] into estrogen stage. Sexual maturation was rapid in mice in female house, when exposed to male urine [23] and reverse when exposed to female urine [24,25]. Possibly such pheromones are in existence in human urine also. The present study was carried out in this line.

In general, male and female sex identified smell of urine of both, but statistically insignificant. Less number of female participants perceived the smell of male urine on the day of ovulation (Figure 1). This indicated that female had less or no attraction towards male at the time of ovulation. Almost similar was experienced on menstruating days, thus two peaks were seen during follicular and another in luteal phase (Figure 1). The olfactory sense towards hypothetical pheromone was not the same during different phases of menstrual cycle (Figure 1). The remaining days showed two peaks. That means attraction to male was more in proliferative and luteal phase. The study indicated that smell emitted by men was not perceived by women equal on all days; it was minimum on ovulation day. Study of Cutler et al. [26] suggested that male pheromones increased the sexual attractiveness of men to women.

Men were more sensitive to the smell of ovulation day urine than of any other day (Figure 1). The study indicated that possibly men could identify women by their smell on this day. This was in conjunction with a month long study conducted by Parks [27] in which couples were instructed not to apply any fragrant substance with the purpose of not masking the natural smell, if any. They were also to record the days on which coitus took place. Maximally this was on the day of ovulation. The attracting factor, authors concluded was the smell emitted from body which was not masked by any unnatural ones. Further, Doty et al. [28] reported that the vaginal odour during the time of ovulation was comparatively more acceptable to men than other phases. Odour exuded by female must be the responsible factor for attraction, stimulation and increase in frequency of coitus during fertile phase [27,29]. Study of Keith et al. [30] showed the difference in odour of pre and post coital vaginal secretion with all probabilities; a pheromone was exuded from women on the day of ovulation to attract men. Answer to the question what could be the possible pheromone is collected from following reports. Michael and Keverne [3] detected a substance from vagina of rhesus monkey, which elicited male sexual activity. This sex attraction was under the influence of estrogen. Michael [31] observed no activity of attraction towards-ovariectomised animals. However, when estradiol was applied to their vagina, they regained the ability of attraction. Anosmic males did not get attached. All these studies strongly suggested that estrogen as a responsible hormone controlling pheromone release.

Female responded in a reverse way that shown by male. Total result was similar to that of an anthropological study conducted in rhesus monkey [2]. Authors showed that grooming behavior of female rhesus monkey fluctuated rhythmically and reached minimum at mid cycle. Paradoxically at this time, males grooming action reached the peak. Maximum intercourse took place at this time. When estradiol was directly applied to the vagina of overiectomised animals, normal males showed interest whereas anosmic male animals did not [3]. Study of Cutler et al. [32] in women showed a constant relationship of estradiol with sexual behavior and not to progesterone or testosterone as known earlier. Probably estradiol induced substance was pheromone in female urine. Possibly, for pheromone release the estrogen level at the time of ovulation was optimal. Also, results of a survey study suggested that human male pheromones increased the sexual attractiveness of men to women [26]. This supports the theory of human estrous [33].

Identifying urine smell from samples of different stages of menstrual cycle, women on the day of ovulation were able to smell that of post ovulatary or luteal phase (67\%) from pregnant women (14\%) (Figure 2). This indicated that ovulating women were more sensitive to progesterone or its metabolites (Figure 2).

Results of the present one month long study showed that many male and female participants were aware of difference in smell of urine of either sex. Those who correctly identified urine samples reported the smell of male as racy or pungent and that of female as piquant or poignant. We consider the responsible olfactory substance in urine as pheromone. The olfactory sensation of women towards pheromones was not the same throughout their menstrual cycle (Figures 1 and 2).

In conclusion, male and female excreted some olfactory substances, through urine. Many were able to recognize it. Male was able to identify female smell of ovulation day much better indicating that male was attracted to female by her smell on the day of ovulation, better than other days. Paradoxically on this day, female perceived the minimum smell emitted by male. This coincided with the observation of Benton [6] that female expressed increased submissiveness than aggressiveness during the time of ovulation.

\section{REFERENCES}

[1] R. Mykytoncyz, "Some Difficulties in the Study of the Function and Composition of Semochemicals in Mammals, Particularly Wild Rabbits, Oryctolagus cuniculus," In: F. J. Rifter, Ed., Chemical Ecology: Odour Communication in Animals, Elsevier North Holland Biochemical Press, Amsterdam, 1979.

[2] R. P. Michael and J. Herbert, "Menstural Cycle Influence Grooming Behavior and Sexual Activity in Rhesus Monkey,” Science, Vol. 140, No. 3566, 1963, pp. 500-501. 
doi:10.1126/science.140.3566.500

[3] R. P. Michael and E. B. Keverne, "Primate Sex Hormones of Vaginal Origin,” Nature, Vol. 225, No. 5227, 1970, pp. 84-85. doi:10.1038/225084a0

[4] M. G. Kalogerakis, "The Role of Olfaction in Sexual Development,” Psychosomatic Medicine, Vol. 25, No. 5, 1963, pp. 420-432.

[5] J. S. Vierling and J. Rock, "Variation in Olfactory Sensitivity to Exaltolide during Menstrual Cycle," Journal of Applied Physiology, Vol. 22, No. 2, 1967, pp. 311-315.

[6] D. Benton, "The Influence of Androstenol-A Putative Human Pheromone on Mod throughout Menstrual Cycle,” Biological Psychology, Vol. 15, No. 3-4, 1982, pp. 249-256. doi:10.1016/0301-0511(82)90047-3

[7] M. C. Mc Clintock, "Menstrual Synchrony and Suppression,” Nature, Vol. 229, 1971, pp. 244-248. doi:10.1038/229244a0

[8] K. P. Skandhan, A. K. Pandya, S. Skandhan and Y. B. Mehta, "Syncronization of Menstruation among Intimates and Kindreds,” Panminerva Medica, Vol. 21, No. 3, 1979, pp. 131-134.

[9] J. L. Veith, M. Buck and S. Getzaf, "Exposure to Men Influence the Occurance of Ovulation in Women," Physiology \& Behavior, Vol. 31, No. 3, 1983, pp. 313-315. doi:10.1016/0031-9384(83)90194-4

[10] B. Nicholson, "Does Kissing Aid Human Bonding by Semochemical Addiction?” British Journal of Dermatology, Vol. 111, No. 5, 1984, pp. 623-627. doi:10.1111/j.1365-2133.1984.tb06635.x

[11] K. Grammer, B. Fink and N. Neave, "Human Pheromones and Sexual Attraction," European Journal of $\mathrm{Ob}$ stetrics \& Gynecology and Reproductive Biology, Vol. 118, No. 2, 2005, pp. 135-142. doi:10.1016/j.ejogrb.2004.08.010

[12] K. P. Skandhan, O. Kaoru, B. M. Mukund and B. Sumangala, "Place of Pheromone in Rape," Advances in Sexual Medicine, Vol. 3, No. 1, 2013, pp. 24-27. doi:10.4236/asm.2013.31005

[13] J. J. Sokolov, R. T. Harris and M. R. Hecker, "Isolation of Substances from Vaginal Secretions Previously Shown to Be Sex Attractant Pheromones in Higher Primates," Archives of Sexual Behavior, Vol. 5, No. 4, 1976, pp. 269274. doi:10.1007/BF01542078

[14] E. O. Wilson and W. H. Bossert, "Chemical Communication among Animals," Recent Progress in Hormone Research, Vol. 19, 1963, pp. 673-716.

[15] H. Varendi, R. H. Porter and J. Winberg, "Does the Newborn Baby Find the Nipple by Smell?” Lancet, Vol. 344, No. 8928, 1994, pp. 989-990. doi:10.1016/S0140-6736(94)91645-4

[16] F. Bonnin, C. Taillard and H. Montagner, "Abilities of the Mothers to Discriminate the Corporeal Odour of Their Newborn,” European Journal of Obstetrics \& Gynecology and Reproductive Biology, Vol. 19, 1990, pp. 165-170.

[17] A. Macfarlane, "Olfaction in the Development of Social Preferences in the Human Neonate," In: R. Porter and M. O’Connor, Eds., Parent Infant Interaction (Ciba Foundation Symposium 33), Elsevier, New York, 1975.
[18] A. Wellar and L. Wellar, "Menstrual Synchrony in Female Couples,” Psychoneuroendocrinology, Vol. 17, No. 2-3, 1972, pp. 171-177. doi:10.1016/0306-4530(92)90055-C

[19] B. M. Pause, "Is the Human Skin a Pheromone Producing Organ?” Journal of Cosmetic Dermatology, Vol. 3, No. 4, 2004, pp. 223-228. doi:10.1111/j.1473-2130.2004.00106.x

[20] D. Troiter, "Vomeronasal Organ and Pheromone," European Annals of Otorhinolaryngology, Head and Neck Diseases, Vol. 128, No. 4, 2011, pp. 184-190. doi:10.1016/j.anorl.2010.11.008

[21] C. J. Dominic and C. D. Pandey, "Failure of Deodorized Males to Induce Estrous in the Wild Mouse," Annales D’Endocrinologie, Vol. 40, No. 3, 1979, pp. 229-234.

[22] H. Jesel and C. Aron, "The Role of Pheromones in the Regulation of Estrous Cycle Duration in the Guinea Pig," Neuroendocrinology, Vol. 20, No. 2, 1976, pp. 97-100.

[23] F. H. Bronson and J. A. Maruniak, "Differential Effects of Male Stimuli on FSH Handprolactin Secretion in Prepubertal Female Mice,” Endocrinology, Vol. 98, No. 5, 1976, pp. 1101-1108. doi:10.1210/endo-98-5-1101

[24] L. C. Drickamar, "Delay of Sexual Maturation in Female House Mice by Exposure to Grouped Female or Urine from Grouped Female,” Journal of Reproduction \& Fertility, Vol. 51, No. 1, 1977, pp. 77-81. doi:10.1530/jrf.0.0510077

[25] L. C. Drickamar, "Seasonal Variation in Acceleration and Delay of Sexual Maturation in Female Mice by Urinary Chemosignals," Journal of Reproduction \& Fertility, Vol. 72, No. 1, 1984, pp. 55-58. doi:10.1530/jrf.0.0720055

[26] W. B. Cutler, E. Friedmann and N. L. Mc Coy, "Pheromonal Influences on Sociosexual Behavior in Men," Archives of Sexual Behavior, Vol. 27, No. 1, 1998, pp. 1-13. doi:10.1023/A:1018637907321

[27] A. S. Parks, "Patterns of Sexuality and Reproduction," Oxford University Press, London, 1976.

[28] R. L. Doty, M. Ford, G. Preti and G. R. Huggins, "Changes in the Intensity and Pleasantness of Human Vaginal Odours during Menstrual Cycle,” Science, Vol. 190, No. 4221, 1975, pp. 1316-1318. doi:10.1126/science.1239080

[29] R. Burton, “The Language of Smell,” Routledge and Kegan Paul, London, 1976.

[30] L. Keith, A. Dravnikes and B. K. Krotoszynski, "Olfactory Study. Human Pheromones," Archives of Gynecology and Obstetrics, Vol. 218, No. 3, 1975, pp. 203-204.

[31] R. P. Michael, "Primate,” In: C. R. Carpenter, Ed., Proceed Second Int Cong, S. Karger, Switzerland, 1969.

[32] W. B. Cutler, C. R. Garcia, G. R. Huggins and G. Preti, "Sexual Behavior and Steroid Levels among Gynecologically Mature Premonopasual Women," Fertility and Sterility, Vol. 45, No. 4, 1986, pp. 496-502.

[33] K. P. Skandhan, A. Rajahariprasad and B. Sumangala, "Support for Human Estrus: Documentation in Ayurveda," The Journal of Sexual Medicine, Vol. 9, No. 1, 2012, pp. 322-325. doi:10.1111/j.1743-6109.2011.02377.x 